\title{
ANALISIS PENILAIAN KONSUMEN TERHADAP KESADARAN MEREK RESTORAN FAST FOOD DI JAKARTA
}

\author{
Megah Wijaya dan Yenli Megawati \\ Email: ymegawati@bundamulia.ac.id
}

\section{Penulis}

Megah Wijaya adalah alumnus Program Studi Manajemen Universitas Bunda Mulia. Yenli Megawati adalah pengajar pada Universitas Bunda Mulia dengan peminatan pada bidang Kuantitatif dan Manajemen Pemasaran.

\section{Abstract}

The purpose of this survey is to know the highest and the lowest brand awareness and brand association of fast food restaurant in Jakarta. In-depth interview and questionnaire are the method the research. There were 200 respondents purposively selected.Data analysis using mean and validity and realibility for questionnaire produce the following results: (1) Top of Mind - KFC (2) Brand Recall McDonald's (3) Brand Recognition - KFC (4) Brand Equity - KFC (5) Brand Preference-McDonald's (6) Brand Uniqueness - McDonald's

\section{Key Words}

Brand, Brand Awareness, Brand Association, Fast Food Restaurant

\section{PENDAHULUAN}

Eksistensi usaha di bidang restoran fast food di Indonesia semakin lama semakin berkembang. Hal ini dibuktikan dengan semakin banyaknya outlet-outlet restoran fast food yang bertambah di pusat perbelanjaan atau mall. Pada tahun 2010, KFC (Kentucky Fried Chicken) melakukan ekspansi bisnis dengan menambah 30 
outlet baru di berbagai kota di Indonesia, McDonald's membuka outlet yang ke 100 di Bulevard Artha Gading dan Hoka-Hoka Bento yang pada awalnya hanya memiliki 3 outlet, yaitu di daerah Pinangsia, Kebon Kacang dan Sabang, kini outlet HokaHoka Bento sudah mencapai 120 outlet yang tersebar di wilayah Jabodetabek, Cilegon, Bandung, Surabaya dan Malang.

Persaingan antar restoran fast food tidak saja hanya sebatas produk, melainkan juga terhadap merek. Merek dianggap sebagai bagian sangat penting dalam menunjang pembelian oleh konsumen. Nilai-nilai merek sendiri dapat dilihat dari pengukuran suatu ekuitas merek. Ekuitas merek berdasarkan penilaian konsumen adalah pengenalan konsumen atas merek dan ingatan konsumen terhadap asosiasi merek yang mendukung kekuatan dan keunikan suatu merek.

Dalam meningkatkan nilai merek (ekuitas merek) diperlukan pemilihan nama merek atau logo yang baik. Kegiatan pemasaran dan komunikasi pemasaran yang baik harus dilakukan agar tercipta asosiasi yang mendukung, kuat dan unik di ingatan konsumen. Untuk mengetahui besarnya minat masyarakat terhadap restoran fast food harus diketahui dahulu seberapa besar kesadaran merek dan seberapa kuat asosiasi merek yang ada dalam benak masyarakat tersebut.

\section{Rumusan Masalah}

Berdasarkan pada latar belakang tersebut, masalah penelitian dirumuskan sebagai berikut:

1. Restoran mana yang merupakan tingkat teratas pada kesadaran merek?

2. Restoran mana yang merupakan tingkat terendah pada kesadaran merek? 


\section{TINJAUAN PUSTAKA}

Penilaian konsumen merupakan suatu proses penilaian yang digunakan untuk membantu perusahaan menentukan pelanggan perusahaan harus menargetkan untuk memaksimalkan keuntungan. (http://searchcrm.techtarget.com/definition/customervaluation). Setidaknya terdapat tiga faktor yang kerap mempengaruhi penilaian konsumen terhadap produk. Ketiganya adalah (1) manfaat atau kepuasan dasar, (2) atribut produk, dan (3) perluasan produk (Bygrave, 1996).

Ambadar dkk (2007: 2) menyatakan bahwa merek merupakan nama, istilah, logo, tanda atau lambang dan kombinasi dua atau lebih dari unsur-unsur tersebut untuk mengidentifikasikan barang-barang atau jasa dari penjual serta membedakannya dari produk pesaing. Rangkuti (2008: 39) menyatakan mengelola ekuitas merek dilakukan guna memberikan nilai bagi perusahaan dan pelanggan. Gambar berikut ini mendukung pernyataan tersebut: 


\section{GAMBAR 1}

\section{KONSEP EKUITAS MEREK}

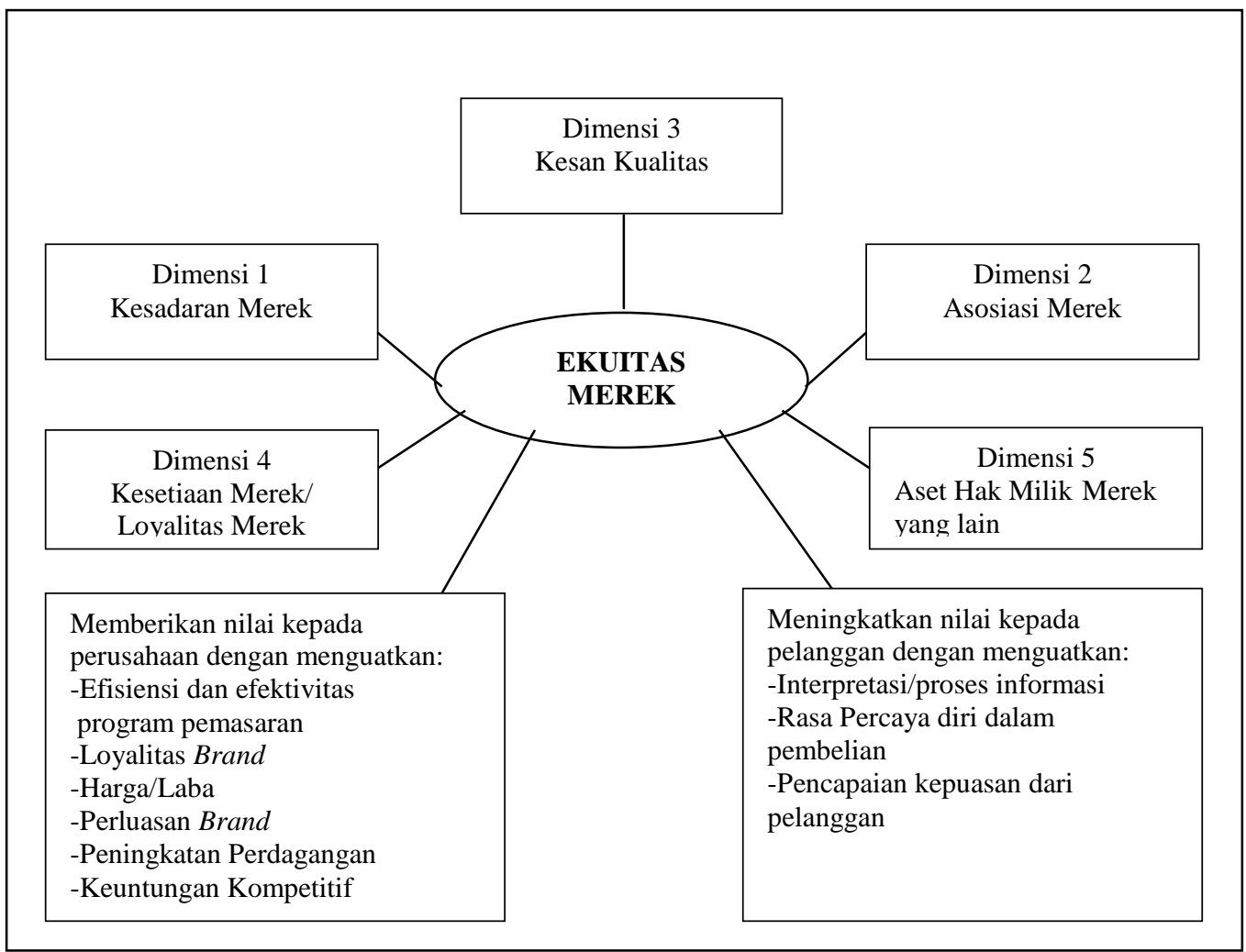

Sumber: Rangkuti, (2008: 39)

\section{Kesadaran Merek (Brand Awareness)}

Suyanto (2007: 80) menyatakan kesadaran merek merupakan kemampuan merek yang dapat dilihat dari seberapa mudah merek tersebut muncul di dalam ingatan pelanggan ketika sedang memikirkan produk tertentu. Berdasarkan Jurnal Management Perceptions of the Importance of Brand Awareness as an Indication of Advertising Effectiveness: Proquest (1990: 141-148) yang dikutip oleh Hoyer dan Brown menyatakan, bahwa kesadaran merek merupakan bagian penting dalam proses komunikasi. Tanpa kesadaran merek, tidak ada efek komunikasi lainnya yang dapat terjadi. 
Berikut ini Gambar 2 Piramida Kesadaran Merek tingkat rendah sampai tingkat tinggi.

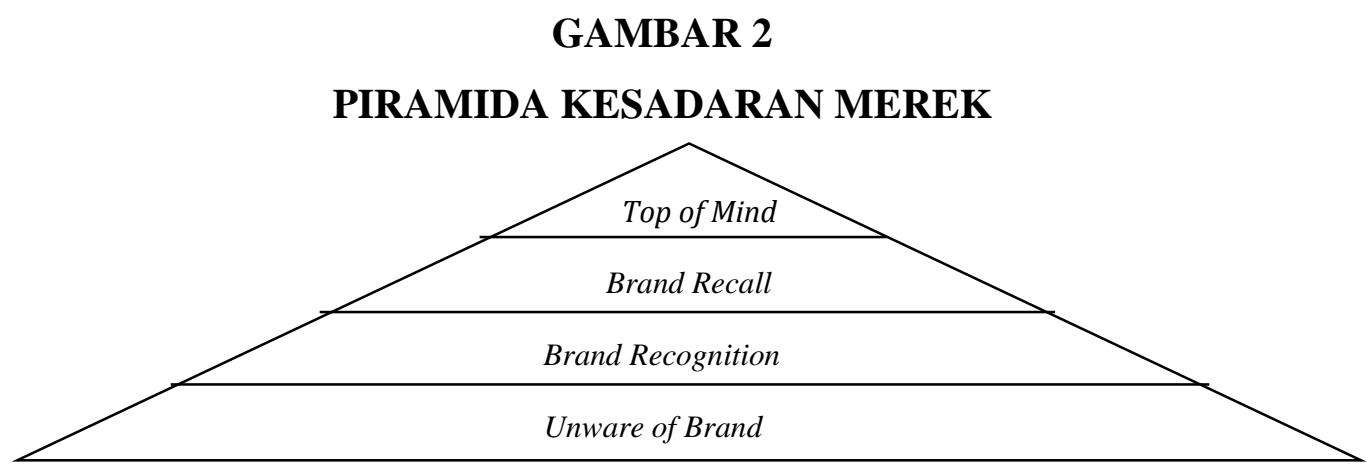

Sumber: Rangkuti, (2008: 40).

\section{Asosiasi Merek (Brand Association)}

Durianto dkk (2001: 69) menyatakan bahwa asosiasi merek merupakan segala kesan yang muncul di benak pelanggan terkait dengan suatu merek. Berdasarkan Jurnal The Measurement and Dimensionality of Brand Associations: Proquest (2000: 350-368) yang dikutip oleh George dkk menyatakan bahwa pemasar menggunakan asosiasi merek untuk membedakan posisi, memperluas merek guna menciptakan sikap positif terhadap merek dan agar pembeli mau membeli suatu merek tertentu.

Keller (2008: 659) menyatakan bahwa ada tiga dimensi asosiasi merek, yaitu:

a. Kekuatan Merek (Brand Strength)

Kekuatan dari asosiasi merek tergantung dari banyaknya kuantitas, seberapa sering seseorang terpikir tentang informasi suatu merek, ataupun kualitas dalam memproses segala informasi yang diterima pelanggan.

b. Kesukaan Merek (Brand Favorability)

Asosiasi merek yang disukai adalah yang bermanfaat bagi pelanggan, yang berhasil disampaikan oleh produk dan juga didukung oleh program pemasaran yang baik. 
c. Keunikan Merek (Brand Uniqueness)

Membuat kesan unik, menunjukkan perbedaan antara merek satu perusahaan dengan perusahaan lain, sehingga dengan adanya keunikan suatu merek yang tidak diperoleh di perusahaan lain maka membuat pelanggan tidak mempunyai alasan untuk menolak merek tersebut.

3. Kesan Kualitas (Perceived Quality)

Susanto (2004: 129) menyatakan persepi kualitas/ kesan kualitas merupakan persepsi pelanggan terhadap keseluruhan kualitas atau keunggulan suatu produk berkenaan dengan maksud yang diharapkan.

4. Kesetiaan Merek (Brand Loyalty)

Kartajaya dan Yuswohady (2005: 177-178) menyatakan bahwa loyalitas merek adalah kesetiaan yang diberikan oleh pelanggan terhadap suatu merek.

\section{GAMBAR 3}

\section{PIRAMIDA LOYALITAS MEREK}

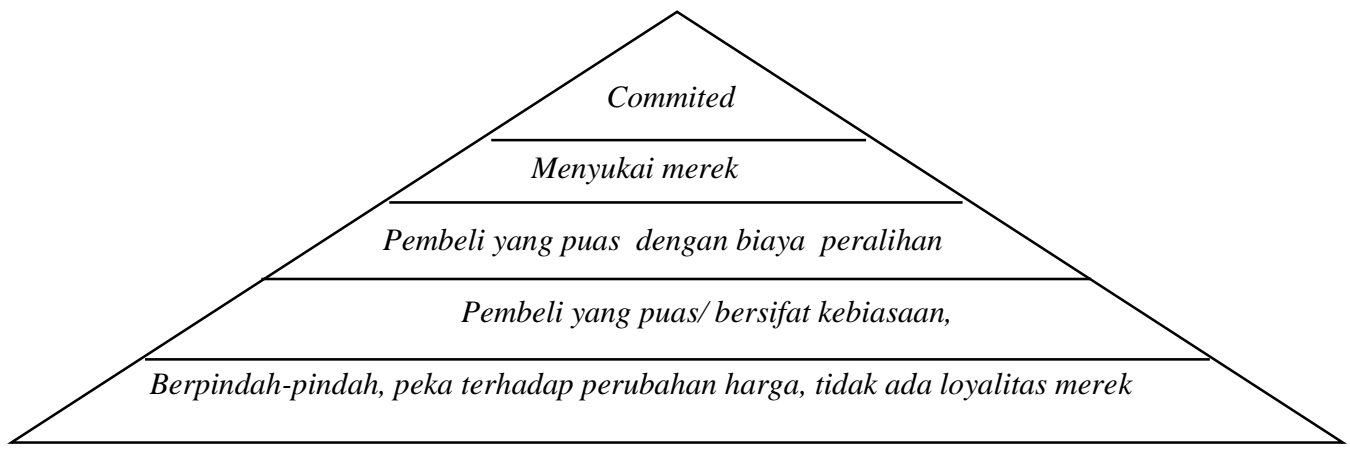

Sumber: Rangkuti, (2008: 61).

5. Nilai Bagi Pelanggan

Simamora (2003 :48) menyatakan ekuitas merek memberikan nilai kepada pelanggan, adalah sebagai berikut:

a. Menguatkan proses informasi

Dengan aset yang dimiliki dapat membantu pelanggan dalam menafsirkan, memproses dan menyimpan informasi yang terkait dengan produk dan merek tersebut. 
b. Menguatkan rasa percaya diri dalam pembelian

Dengan ekuitas merek dapat mempengaruhi rasa percaya diri pelanggan dalam pengambilan keputusan pembelian atas dasar pengalaman masa lalu dalam penggunaan ataupun kedekatan dengan merek dan berbagai karakteristik merek.

c. Menguatkan pencapaian kepuasan dari pelanggan

Dalam kenyataannya, kesan kualitas dan asosiasi merek dapat mempertinggi tingkat kepuasan pelanggan dalam penggunaan produk.

6. Nilai Bagi Perusahaan

Durianto (2001: 6-7) menyatakan nilai yang diberikan ekuitas merek bagi perusahaan adalah sebagai berikut:

a. Menguatkan efisiensi dan efektivitas program pemasaran

b. Mempengaruhi alasan pembelian

c. Menguatkan harga / laba

d. Perluasan merek

e. Peningkatan perdagangan

f. Keuntungan kompetitif

Alamsyah (2009: 2-3) menyatakan bahwa Merriam pada tahun 1951 mengatakan fast food atau makanan siap saji dapat diartikan sebagai makanan yang dapat disiapkan dan disajikan dengan cepat. Makanan lain yang dapat dikategorikan sebagai fast food adalah juga makanan yang dijual di toko atau restoran dengan memerlukan sedikit persiapan dan penyajian untuk dibawa pulang dalam bentuk kemasan. Fast food ada beberapa jenis, yaitu:

a. Fast food Amerika. Di Amerika pada umumnya fast food yang dijual adalah ayam goreng, hamburger (burger), kentang goreng, chicken nugget, pizza, dan es krim (sebagai pelengkap). Namun belakangan banyak juga yang menjual jenis makanan yang bisa disajikan lebih lambat (slower) seperti salad, chili, mashed potatoes, dan sejenisnya. 
b. Fast food Eropa. Di Eropa makanan jenis fast food berupa hamburger, pizza dan sebagainya.

c. Fast food Timur Tengah. Di Timur Tengah yang termasuk kategori fast food adalah kebab.

d. Fast Food Asia Timur. Di Asia Timur berbagai jenis makanan berbasis mie bisa disebut fast food.

e. Fast food asli Indonesia. Di Indonesia, bakmi dan mie bakso bisa juga disebut fast food.

\section{METODOLOGI PENELITIAN}

Jenis penelitian yang digunakan adalah penelitian deskriptif kuantitatif. Metode pengumpulan data yang digunakan untuk penelitian ini terbagi dua bagian, yaitu wawancara dan kuesioner. Populasi dalam penelitian ini adalah orang yang pernah mengkonsumsi makanan atau minuman di restoran fast food yang berada di Jakarta. Penelitian ini menggunakan sampel sebanyak 200 responden. Kriteria yang menjadi sampel dalam penelitian ini adalah responden yang pernah makan atau minum di restoran fast food di Jakarta, berusia dari 15 sampai 38 tahun ke atas. Karakter sampel yang dianalisis adalah tingkat usia, penghasilan dan jenis pekerjaan. Teknik pemilihan sampel yang digunakan dalam penelitian ini adalah teknik non probabilitas sampling karena jumlah populasi sampel tidak dapat diidentifikasi secara pasti. Dalam pemilihan sampel tersebut menggunakan judgmental sampling, dimana keputusan mengenai siapa yang dapat ditetapkan sebagai sampel didasarkan pada pertimbangan peneliti. 
Pengolahan data dilakukan dengan menganalisis penilaian konsumen terhadap kesadaran merek dan asosiasi merek dengan sebelumnya melakukan uji validitas dan reliabilitas terlebih dahulu. Untuk menganalisis validitas dan reliabilitas data, maka dilakukan analisis data dengan menggunakan SPSS 17 (Statistical Package for Social Science). untuk menganalisis penilaian konsumen terhadap kesadaran merek dan asosiasi merek pada pelanggan restoran fast food di Jakarta, maka dilakukan analisis data dengan menggunakan Microsoft Excel 2007 dengan menggunakan analisis persentase.

\section{HASIL ANALISIS}

Berikut ini merupakan hasil pengolahan kuesioner dari segi demografi responden yang merupakan pelanggan restoran fast food di Jakarta dan berjumlah 200 sampel.

1. Usia Responden

\section{TABEL 1}

\section{USIA RESPONDEN}

\begin{tabular}{|l|l|l|}
\hline Usia & Jumlah & Persentase \\
\hline $15-20$ Tahun & 105 & $52.5 \%$ \\
\hline $21-26$ Tahun & 47 & $23.5 \%$ \\
\hline 27 - 32 Tahun & 18 & $9 \%$ \\
\hline 33 - 38 Tahun & 12 & $6 \%$ \\
\hline$>38$ Tahun & 18 & $9 \%$ \\
\hline Total & 200 & $100 \%$ \\
\hline
\end{tabular}

Sumber: Hasil pengolahan kuesioner 2010

Berdasarkan tabel di atas dapat penulis jelaskan, sebagian besar usia responden berusia 15 sampai 20 tahun dengan jumlah responden 105 responden $(52,5 \%)$. 
2. Penghasilan Responden

TABEL 2

PENGHASILAN RESPONDEN

\begin{tabular}{|c|c|c|}
\hline Penghasilan & Jumlah & Persentase \\
\hline$<\operatorname{Rp} 500.000,00$ & 119 & $59.5 \%$ \\
\hline Rp 500.000,00 - Rp 1.000.000,00 & 19 & $9.5 \%$ \\
\hline Rp 1.000.000,00 - Rp 1.500.000,00 & 3 & $1.5 \%$ \\
\hline Rp 1.500.000,00 - Rp 2.000.000,00 & 2 & $1 \%$ \\
\hline$>\mathrm{Rp} 2.000 .000,00$ & 57 & $28.5 \%$ \\
\hline Total & 200 & $100 \%$ \\
\hline
\end{tabular}

Sumber: Hasil pengolahan kuesioner 2010

Berdasarkan tabel di atas dapat penulis jelaskan, sebagian besar penghasilan responden lebih kecil dari Rp 500.000,00 dengan jumlah responden 119 responden $(59,5) \%$.

3. Jenis Pekerjaan

TABEL 3

JENIS PEKERJAAN RESPONDEN

\begin{tabular}{|l|l|l|}
\hline Jenis Pekerjaan & Jumlah & Persentase \\
\hline Pelajar/ Mahasiswa & 159 & $80 \%$ \\
\hline Pegawai & 23 & $12 \%$ \\
\hline Pengusaha/ Wiraswasta & 4 & $2 \%$ \\
\hline Ibu Rumah Tangga & 13 & $7 \%$ \\
\hline Guru & 1 & $1 \%$ \\
\hline TOTAL & 200 & $100 \%$ \\
\hline
\end{tabular}

Sumber: Hasil pengolahan kuesioner 2010

Berdasarkan tabel di atas dapat penulis jelaskan, sebagian besar jenis pekerjaan responden pelajar dan mahasiswa dengan jumlah responden 159 responden $(80) \%$. 
Uji validitas dan reliabilitas dilakukan untuk menguji kuesioner yang dibagikan kepada responden. Berdasarkan hasil pengolahan data dan analisis data menggunakan program SPSS 17 (Statistical Package for Social Science), kuesioner yang disebarkan kepada responden menunjukkan bahwa:

a. Uji Validitas dan Reliabilitas Asosiasi Merek

TABEL 4

VALIDITAS ASOSIASI MEREK

Item-Total Statistics

\begin{tabular}{|l|l|l|l|l|}
\hline & $\begin{array}{l}\text { Scale Mean if Item } \\
\text { Deleted }\end{array}$ & $\begin{array}{l}\text { Scale Variance if } \\
\text { Item Deleted }\end{array}$ & $\begin{array}{l}\text { Corrected Item- } \\
\text { Total Correlation }\end{array}$ & $\begin{array}{l}\text { Cronbach's Alpha } \\
\text { if Item Deleted }\end{array}$ \\
\hline Asosiasi Merek & 6.57 & 7.231 & .513 & .773 \\
Asosiasi Merek & 6.69 & 7.383 & .402 & .785 \\
Asosiasi Merek & 6.54 & 7.506 & .413 & .783 \\
Asosiasi Merek & 6.58 & 7.361 & .454 & .779 \\
Asosiasi Merek & 6.55 & 7.526 & .401 & .784 \\
Asosiasi Merek & 6.76 & 7.543 & .331 & .793 \\
Asosiasi Merek & 6.56 & 7.263 & .506 & .773 \\
Asosiasi Merek & 6.63 & 7.159 & .512 & .773 \\
Asosiasi Merek & 6.74 & 7.249 & .447 & .771 \\
Asosiasi Merek & 6.62 & 7.153 & .522 & .776 \\
Asosiasi Merek & 6.54 & 7.366 & .479 & \\
\hline
\end{tabular}

Sumber: Hasil Pengolahan Data 2010 dengan SPSS 17

Berdasarkan hasil analisis, angka-angka yang ada pada kolom Corrected Item-Total Correlation > 0,2 maka instrumen pengukuran tersebut dinyatakan valid.

TABEL 5

\section{RELIABILITAS ASOSIASI MEREK}

Reliability Statistics

\begin{tabular}{|l|l|}
\hline $\begin{array}{l}\text { Cronbach's } \\
\text { Alpha }\end{array}$ & N of Items \\
\hline 795 & 11 \\
\hline
\end{tabular}

Sumber: Hasil Pengolahan Data 2010 dengan SPSS 17

Berdasarkan tabel di atas terlihat bahwa kuesioner tersebut bersifat reliable, karena Cronbach's alpha asosiasi merek sebesar 0,795 > dari 0,60. 
Dalam menganalisis penilaian konsumen terhadap kesadaran merek dan asosiasi merek pada pelanggan restoran fast food di Jakarta, maka dilakukan analisis data dengan menggunakan Microsoft Excel 2007, dengan metode Analisis Persentase. Hasil pengolahan data dan analisis data kesadaran merek responden adalah sebagai berikut:

\section{a. Top of Mind}

KFC merupakan merek restoran fast food yang paling banyak disebut pertama kali oleh responden, yaitu sebanyak 106 dengan persentase 53\%. Jadi KFC merupakan restoran fast food yang menjadi Top of mind-Kesadaran Merek. McDonald's merupakan merek restoran fast food yang disebut pertama kali pada peringkat ke 2 dengan persentase $19.5 \%$ (39 responden). Texas dan CFC menduduki peringkat ke 6 dengan persentase 4\% (8 responden). Sedangkan Wendy's menduduki peringkat ke 7 dengan persentase $3 \%$ (6 responden).

Berikut ini merupakan tampilan dari analisis kesadaran merek dalam tabel:

TABEL 6

TOP OF MIND

\begin{tabular}{|l|l|l|l|}
\hline Peringkat & Nama Merek & Jumlah & Persentase \\
\hline 1 & KFC & 106 & $53 \%$ \\
\hline 2 & MC DONALD'S & 39 & $19.5 \%$ \\
\hline 3 & A \& W & 8 & $4 \%$ \\
\hline 4 & PIZZA HUT & 10 & $5 \%$ \\
\hline 5 & HOKA-HOKA BENTO & 9 & $5 \%$ \\
\hline & TEXAS & 8 & $4 \%$ \\
\cline { 2 - 4 } & CFC & 8 & $4 \%$ \\
\hline 7 & WENDY'S & 6 & $3 \%$ \\
\hline 8 & TONY JACK'S & 4 & $2 \%$ \\
\hline 9 & POPEYES & 2 & $1 \%$ \\
\hline Total & & 200 & $100 \%$ \\
\hline
\end{tabular}

Sumber: Hasil pengolahan kuesioner 2010 


\section{b. Brand Recall}

McDonald's merupakan merek restoran fast food yang paling banyak disebut oleh responden tanpa dibantu dengan alat bantuan (daftar merek), yaitu sebanyak 23,71 \% (sebanyak 78 yang menjawab dari total 329 jawaban). Jadi McDonald's merupakan restoran fast food yang menjadi Brand Recall-Kesadaran Merek. KFC menduduki peringkat ke 2 Brand Recall dengan perolehan nilai 19,15\% (sebanyak 63 resonden yang menjawab dari total 329 jawaban). CFC dan Texas menduduki peringkat ke 5 dengan memperoleh nilai 10,33\% (sebanyak 34 responden yang menjawab dari total 329 jawaban), sedangkan Wendy's menduduki peringkat ke 6 dengan perolehan nilai 7,29\% (sebanyak 24 responden yang menjawab dari total $329 \%)$.

Berikut ini merupakan tampilan dari analisis kesadaran merek dalam tabel:

TABEL 7

\section{BRAND RECALL}

\begin{tabular}{|l|l|l|l|}
\hline Peringkat & Nama Merek & Jumlah & Persentase \\
\hline 1 & MC DONALD'S & 78 & $23.71 \%$ \\
\hline 2 & KFC & 63 & $19.15 \%$ \\
\hline 3 & A \& W & 41 & $12.46 \%$ \\
\hline 4 & HOKA-HOKA BENTO & 38 & $11.55 \%$ \\
\hline 5 & CFC dan TEXAS & 34 & $10.33 \%$ \\
\hline 6 & WENDY'S & 24 & $7.29 \%$ \\
\hline 7 & BURGER KING & 16 & $4.86 \%$ \\
\hline 8 & TONY JACK'S & 9 & $2.74 \%$ \\
\hline 9 & PIZZA HUT & 7 & $2.13 \%$ \\
\hline 10 & POPEYES & 5 & $1.52 \%$ \\
\hline 11 & DONER KEBAB & 5 & $1.52 \%$ \\
\hline 12 & DOMINO'S PIZZA & 3 & $0.91 \%$ \\
\hline 13 & BROOSTER & 3 & $0.91 \%$ \\
\hline 14 & KRISPY KREME & 2 & $0.61 \%$ \\
\hline 15 & DUNKIN DONUT'S & 1 & $0.30 \%$ \\
\hline Total & & 329 & $100 \%$ \\
\hline
\end{tabular}

Sumber: Hasil pengolahan kuesioner 2010 


\section{c.Brand Recognition}

KFC merupakan merek restoran fast food yang paling dikenal oleh responden meskipun dilihat dengan menggunakan alat bantu, berupa gambar merek. Responden yang mengenal merek KFC dengan menggunakan alat bantu berupa gambar merek, yaitu sebanyak 19\% (sebanyak 190 responden yang menyatakan mengenal merek KFC). McDonald's menduduki peringkat ke 2 dengan nilai 18,6\% (sebanyak 186 responden yang menyatakan mengenali gambar merek McDonald's). Texas menduduki peringkat ke 3 dengan perolehan nilai 17,4\% ( sebanyak 174 responden yang menyatakan mengenal merek Texas). CFC menduduki peringkat ke 4 dengan memperoleh nilai $17,1 \%$ (sebanyak 171 responden yang menyatakan mengenal merek CFC). Sedangkan, Wendy's menduduki peringkat terakhir dengan memperoleh nilai 12,8\% (sebanyak 151 responden yang menyatakan mengenal merek Wendy's).

TABEL 8

BRAND RECOGNITION

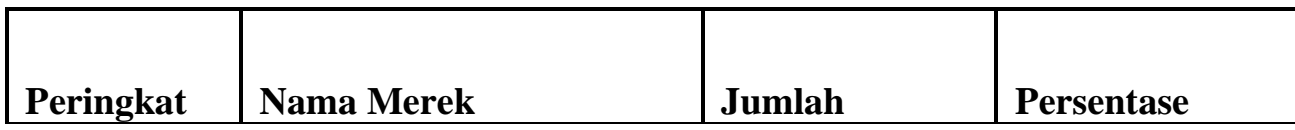

\begin{tabular}{|l|l|l|l|}
\hline 1 & KFC & 190 & $19 \%$ \\
\hline 2 & MC DONALD'S & 186 & $18.6 \%$ \\
\hline 3 & TEXAS & 174 & $17.4 \%$ \\
\hline 4 & CFC & 171 & $17.1 \%$ \\
\hline 5 & WENDY'S & 151 & $15.1 \%$ \\
\hline 6 & Tidak Memilih & 128 & $12.8 \%$ \\
\hline Total & & 1000 & $100 \%$ \\
\hline
\end{tabular}

Sumber: Hasil pengolahan kuesioner 2010 


\section{KESIMPULAN}

Berdasarkan hasil analisis, kesimpulan penelitian ini adalah:

1. Restoran yang merupakan tingkat teratas pada kesadaran merek antara lain:

a. Dari lima restoran fast food yang diuji (KFC, McDonald's, CFC, Texas dan Wendy's) KFC merupakan restoran fast food yang menjadi Top of mind-Kesadaran Merek.

b. Dari lima restoran fast food yang diuji (KFC, McDonald's, CFC, Texas dan Wendy's) McDonald's merupakan restoran fast food yang menjadi Brand Recall-Kesadaran Merek

c. Dari lima restoran fast food yang diuji (KFC, McDonald's, CFC, Texas dan Wendy's) KFC merupakan restoran fast food yang menjadi Brand Recognition-Kesadaran Merek. Dengan demikian, KFC merupakan merek yang memiliki nilai paling tinggi untuk merek yang disebut oleh responden dengan dibantu daftar merek.

2. Restoran yang merupakan tingkat terendah pada kesadaran merek dan asosiasi merek, antara lain sebagai berikut:

a. Dari lima restoran fast food yang diuji (KFC, McDonald's, CFC, Texas dan Wendy's) Wendy's merupakan restoran fast food yang menjadi peringkat terakhir Top of mind-Kesadaran Merek.

b. Dari lima restoran fast food yang diuji (KFC, McDonald's, CFC, Texas dan Wendy's) Wendy's merupakan restoran fast food yang menjadi peringkat terakhir Brand Recall-Kesadaran Merek.

c. Dari lima restoran fast food yang diuji (KFC, McDonald's, CFC, Texas dan Wendy's) Wendy's merupakan restoran fast food yang menjadi peringkat terakhir Brand Recognition-Kesadaran Merek. 


\section{Saran}

1. CFC diharapkan mampu membuat pandangan masyarakat menjadi baik terhadap CFC. Hal ini dapat dilakukan dengan melakukan pengiklanan yang menunjukan kebaikan-kebaikan CFC, agar pandangan masyarakat terhadap image CFC menjadi baik.

2. Restoran Wendy's diharapkan lebih banyak beriklan, sebagai pengulangan untuk pengingatan merek. Semakin sering beriklan akan dapat menimbulkan kesadaran merek. Wendy's diharapkan membuat menu baru yang lebih sehat serta membuat slogan yang sesuai.

\section{DAFTAR PUSTAKA}

Ambadar, J., Abidin M., \& Yanty I. (2007), Mengelola Merek, Yayasan Bina Karsa Mandiri, Jakarta.

Durianto, D., Sugiarto, \& Tony S. (2001), Strategi Menaklukkan Pasar Melalui Riset Ekuitas \& Perilaku Merk, PT Gramedia Pustaka Utama, Jakarta.

Kartajaya, H., \& Yuswohady, (2005), Attracting Tourists, Traders, Investors: Strategi Memasarkan Daerah di Era Otonomi, PT Gramedia Pustaka Utama, Jakarta.

Keller, K.L., (2008), Strategic Brand Management Building, Measuring, and Managing Brand Equity, PT. Pearson Education, Delhi.

Rangkuti, F. (2008), The Power of Brands: Teknik Mengelola Brand Equity dan Strategi Pengembangan Merek + Analisis Kasus dengan SPSS, PT Gramedia Pustaka Utama, Jakarta.

Simamora, B. (2003), Aura Merek, PT Gramedia Pustaka Utama, Jakarta.

Susanto, A.B. \& Wijanarko, (2004), Power branding: membangun merek unggul dan organisasi pendukungnya, PT. Mizan Publika, Jakarta.

Suyanto, M. (2007), Marketing Strategy Top Brand Indonesia, CV Andi Offset, Yogyakarta.

http://searchcrm.techtarget.com/definition/customer-valuation 